\title{
Erectile Dysfunction in Male with Glans Penis Apocrine Hydrocystoma: Organic or Psychogenic?
}

\author{
Ion Dumbraveanu1 ${ }^{1}$, Iurie Arian1, Andrei Munteanu' ${ }^{2}$, Daniela Catereniuc ${ }^{3}$, Adrian Tanase ${ }^{1}$ \\ ${ }^{1}$ Department of Urology and Surgical Nephrology, State University of Medicine and Pharmacy "Nicolae Testemitanu”, Chisinau, \\ Republic of Moldova \\ ${ }^{2}$ Department of Morphopathology, State University of Medicine and Pharmacy “Nicolae Testemitanu”, Chisinau, \\ Republic of Moldova \\ ${ }^{3}$ Department of Neurology No. 2, State University of Medicine and Pharmacy "Nicolae Testemitanu”, Chisinau, \\ Republic of Moldova \\ Email: iondumbraveanu@yahoo.com
}

How to cite this paper: Dumbraveanu, I., Arian, I., Munteanu, A., Catereniuc, D. and Tanase, A. (2017) Erectile Dysfunction in Male with Glans Penis Apocrine Hydrocystoma: Organic or Psychogenic? Advances in Sexual Medicine, 7, 131-138. https://doi.org/10.4236/asm.2017.73010

Received: June 14, 2017

Accepted: July 7, 2017

Published: July 10, 2017

Copyright (C) 2017 by authors and Scientific Research Publishing Inc. This work is licensed under the Creative Commons Attribution International License (CC BY 4.0).

http://creativecommons.org/licenses/by/4.0/

\begin{abstract}
The location of the apocrine hydrocystoma in the penis region is rare. We present a case where we evaluated the erectile function of a patient presenting such an asymptomatic formation. We assessed the psychogenic component of the erectile dysfunction based on the association of the somatic component of the cyst with the patient's inability to focus on sexual intercourse. The fear of traumatization of the cyst during sexual intercourse was considered as a triggering factor of the chain of insufficient or unsuccessful erections, and the sexual performance anxiety as a factor in maintaining this erectile dysfunction. Apparently, an organic cause induced an erectile dysfunction, through non-organic (predisposition, triggering and maintenance) mechanisms.
\end{abstract}

\section{Keywords}

Penile Cyst, Apocrine Hydrocystoma, Erectile Dysfunction, Psychogenic Erectile Dysfunction, Sexual Performance Anxiety

\section{Introduction}

Apocrine hydrocystoma is a benign cystic tumor with a more frequent localization on the face zone, ears, scalp, chest, shoulders, or vulva [1].

According to histological criteria, the literature describes both apocrine and eccrine hydrocystoma, the apocrine ones being well delimited, translucent, which may be solitary (Smith type) and multiple (Robinson type), with a smooth 
surface, and the color that ranges from that of the skin to a grey or blue-black, more often only the region of the cyst being affected [2]. It can be identified at any age and in both sexes [3] [4].

The location of the apocrine hydrocystoma in the penis region is rare [1] [2] [3] [4]. In the literature only 4 similar cases have been reported according to our data. At the same time, reported cases do not refer to the evaluation of erectile function of patients presenting such formations in the penis region, but only to the fact that they are asymptomatic, grow slowly in size and can reach a diameter of $1 \mathrm{~cm}$ and more [2].

By presenting the case and literature review, the authors have proposed to explain the mechanism of occurrence of erectile dysfunction in patients with benign penile cystic formations.

\section{Case Report}

Patient, 34 years old, European, primarily addresses with complaints of erectile dysfunction spontaneously installed for about 3 months. The patient evaluation by the IIEF questionnaire reveals a mild-moderate erectile dysfunction, diminishing satisfaction from intercourse and general satisfaction (IIEF-5 $=13$ points).

The patient does not present any acute or chronic pathologies. He was not and is not a user of any long-term drugs or nutritional supplements (including those used in sports). From history, it is known that he has been married for 10 years, has a child of 9 years old, his sexual life was satisfying until the onset of erectile dysfunction. With his partner, he communicates freely the couple's issues including those sexual, the partner manifests support and understanding during the time of sexual complaints.

At the physical examination-normostenic constitution, absent abdominal obesity, two cystic formations are noticed, communicating, located in the base region of the glans penis and urethral meatus (Figure 1).

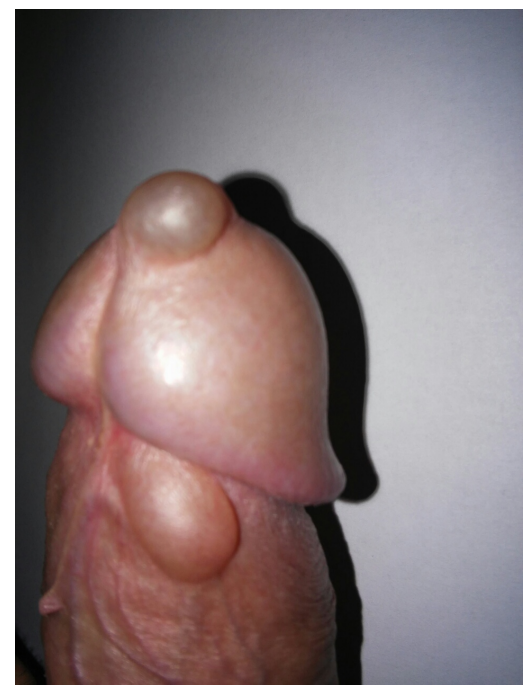

Figure 1. Penile macroscopic aspectpre-intervention. 
The ultrasonographical exam has determined the projection of the communication channel laterally to the frenulum. Paraclinical and laboratory investigations have not identified any significant pathological changes (Testosterone, SHBG, TSH, LH, FSH, Prolactin-in normal range).

The patient does not describe an exact moment of the appearance of the cystic formation, but notes that the secondary cyst, located in the region of the base of the penile gland, appeared about two years ago, probably because of the pressure exerted during sexual activity. In flaccid state, during exercising pressure on one cyst, the liquid content movement is appreciated in the second and vice versa.

Last year, the patient noted the slow increase in volume of both cysts, and the increasing of the cyst capsule's tension during erection-disturbing tension that made him focus his senses on it, during the sexual act. Additionally, he noticed the reduction in thickness of the superficial tissue of the apical cyst, with a tendency to break, which induced a state of fear not to traumatize it. Consequentlylimiting the amplitude of friction movements. The erectile dysfunction began with the inability to maintain the erection, then the impossibility of obtaining a repeated one, later with the impossibility of starting the sexual act in most of the situations.

The onset time of the erectile dysfunction is described by the patient as it was preceded by sexual acts in which he was unable to maintain the erection, as well as with the end of the sexual intercourse due to the impossibility of achieving a repeated erection, afterwards a condition was installed in which the erection was insufficient to begin sexual intercourse.

Following clinical, paraclinical and laboratory investigations of the patient, the diagnosis of: Apocrine hydrocystoma of the glans penis, Moderate psychogenic erectile dysfunction, Sexual performance anxiety, was established.

Macroscopic appearance of the double communicating cyst: translucent, unicameral, etc. suggested the diagnosis of an apocrine hydrocystoma, and less suggestive of an eccrine type. However, the histological confirmation established the final diagnosis (Figure 2 and Figure 3).

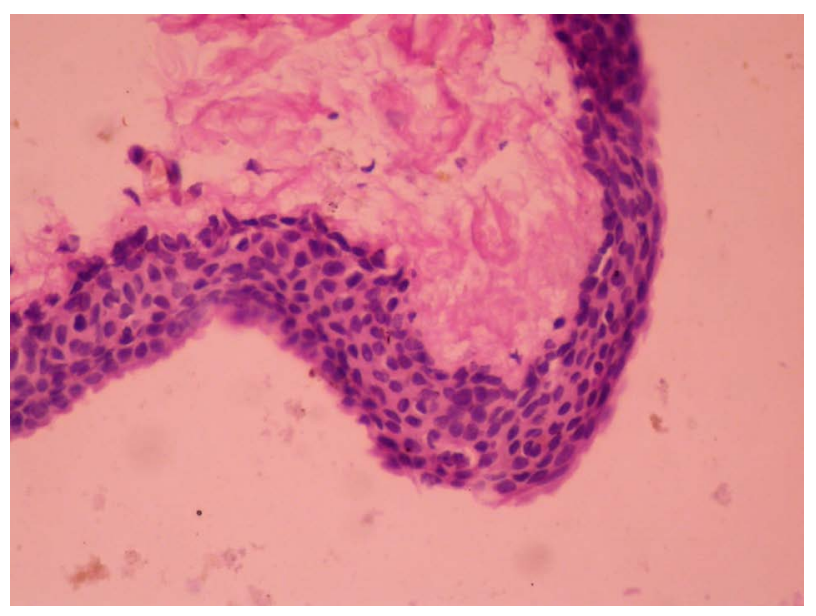

Figure 2. Squamous epithelium passes on the cyst wall. Hematoxylin eosin staining $(400 \times)$. 
The rationale of determining psychogenic erectile dysfunction is based on the association of the somatic component of the cyst with the patient's inability to focus on sexual intercourse. The fear of traumatization of the cyst during sexual intercourse was considered as a trigger factor of the chain of insufficient or unsuccessful erections, and the sexual performance anxiety as a factor in maintaining this erectile dysfunction.

Apparently, an organic cause induced an erectile dysfunction, through nonorganic mechanisms. It was decided to resolve the cyst as a treatment tactic of the erectile dysfunction by removing the trigger factor. The patient underwent surgery with the excision of both cysts and the communicating channel (Figure 4).

Patient evaluation at 3 months post-intervention identified the absence of local recurrence and sexual recovery with the absence of an erectile dysfunction (IIEF-5 $=24$ points). The following evaluation after 6 and 9 months after intervention still has no complaints from the patient side.

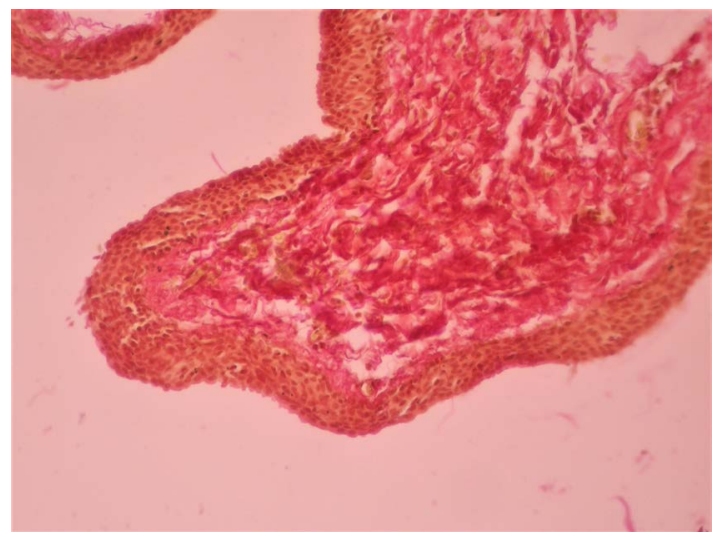

Figure 3. Chronic inflammatory changes (cystic wall sclerosis). Picrofuscin von Gieson staining (400×).

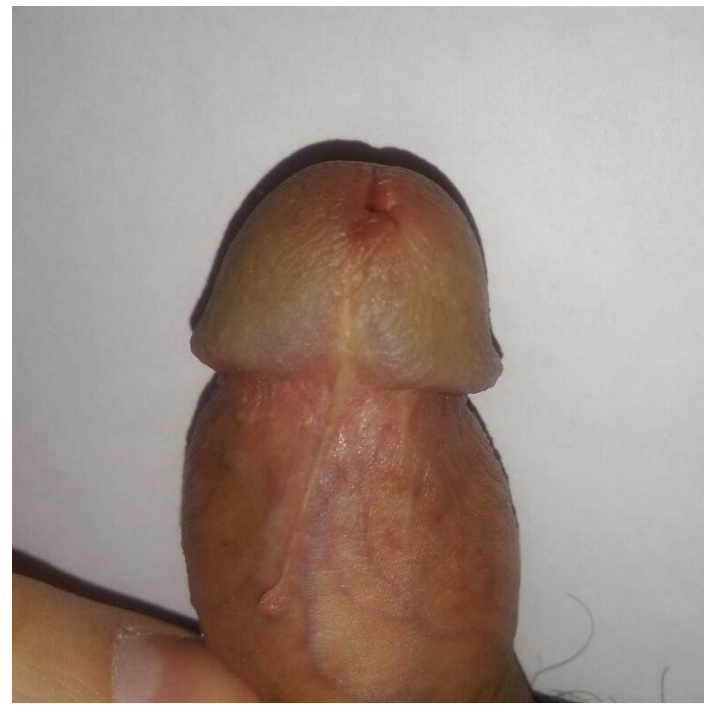

Figure 4. Penile macroscopic aspect 3 months postintervention. 


\section{Discussion}

Asymptomatic cystic formations located in the penile region are rarely considered as triggering factors for erectile dysfunction. Absence of pain and patient embarrassment in relation to the cosmetic aspect requires the exclusion of psychogenic factors as well for the impaired erectile function.

Psychogenic factors can predispose, trigger, or maintain the erectile dysfunction [5]. Predisposing factors are those factors that indicate the vulnerability of a person for the appearance of erectile dysfunction at some point, and the trigger factors are directly those factors leading to the first erectile failure at a certain moment and in a certain situation.

In the case of the questioned patient, one of the major factors of its predisposition for erectile dysfunction was the cognitive, determined by its beliefs on sexuality. These sexual beliefs/sex myths have influenced the patient in interpreting the events related to his erectile function. Zilbergeld (1999) describes a high proportion of sex myths in men with erectile dysfunction, such as: "a man always wants and is ready for sex", "a man always can", "sex consists of a rigid penis and what you can do with it", and "sex is equal to intercourse". The patient was convinced that his role as a man namely consists in the ability to satisfy the sexual partner, which is why even after the first erectile failure he associated thoughts that he has a potency problem and that his wife may leave him.

As trigger factor, we analyzed the disturbance of attention during intercourse by focusing on the sensations in the cyst, and with the subsequent protective correction of the friction amplitude. Thus, studies on healthy patients have established that attention to sexual stimuli triggers sexual arousal, while distracting attention from sexual intercourse (either because of an internal stimulus, or under the action of an external stimulus) leads to inhibition of sexual arousal [6]. Several studies have shown that performance demand has had a negative impact on men with erectile dysfunction, but not on those without sexual problems. Heiman and Rawland (1983) have discovered that men without sexual dysfunction showed a stronger sexual genital excitation when they were asked to get an erection as quickly as possible (performance demand) compared with the demand to think of some pleasant internal sensations (focusing on sensations demand). However, men with sexual dysfunction have shown contradictory effect, and had a better erection focusing on sensations than on performance demand [7].

In the case of the given patient, as a non-erotic stimulus can be considered the penile cyst, and the trigger moment-the stage in which the patient began to focus his attention on the changes that occurred at the penis level (enlargement in cyst size and the fear of its potential lesion). As a provocative mechanism, we consider that distraction caused the onset of erectile dysfunction by lowering the rigidity of the penis, and focusing the attention on the possibility of losing the erection induced a state of anxiety over an eventual erectile failure.

Performance anxiety is a trigger to initiate or maintain the erectile dysfunction [8]. In medical practice, performance anxiety plays a decisive role in the 
evolution and treatment of patients with sexual dysfunction, because it is a pathological phenomenon involving several factors: cognitive, affective, behavioral, and psychological. Performance anxiety can be caused by any sexual stimulation (invitation for sexual intercourse, a sex image, a very sexual partner or decreasing erectile rigidity during sexual intercourse) which the man associates with erectile capacity or incapacity [9]. If the sexual stimulus is associated with some negative emotions dependent on previous sexual experiences, then the patient will most likely experience an erectile failure. Negative emotions can cause erectile failure through two basic mechanisms: distracting attention from pleasant sexual stimuli and increasing sympathetic tone leading to penile smooth muscle contraction [10] [11] [12]. Increasing the sympathetic tone caused by any type of performance anxiety and, therefore, the inclusion of both mechanisms: 1) norepinephrine release from sympathetic nerve endings of the vegetative nerves that innervate the cavernous body and 2) the excretion of adrenaline from the adrenal glands in the bloodstream intervening both at the onset and the maintenance of erection, -interacts with both the onset of erection and the maintenance of it. It has also been suggested that continuous erectile failure can lead to the de-erotization of the received erotic stimuli, resulting in a decrease in sexual arousal [13].

In the case of the patient, performance anxiety can be considered an associated mechanism to the trigger factor and respectively-the main mechanism of maintenance. The changes in time of the cyst: the appearance of the secondary communicable cyst, their increase in volume and eminence of trauma have become the subject of distraction of the patient triggering reduction in penile rigidity during penetration. Reduced stiffness appears to be a result of the lowered patient involvement in intercourse with the attenuation of the perception of pleasant sex stimuli and reducing sexual arousal (physiological factor needed to maintain erection). Feeling weak erection, at the cognitive level triggered the fear of losing it (including because of its propensity to this from the point of view of his beliefs about sex, etc.) associating the sympathetic mechanism that together led to that first erectile failure. Subsequent maintenance of erectile dysfunction was due to the embarrassing cyst persistence and to the developed performance anxiety.

Organic or psychogenic cause? How can the apocrine hydrocystoma of the penis gland be considered in the context of evaluating the causes that led to erectile dysfunction?

In the case of the given patient, we can talk about a gradually installed erectile dysfunction, but determined by a well-defined situation by the patient. At the same time, the patient did not perceive any painful sensations in the cyst, describing even the absence of the cosmetic embarrassment in relation to the cyst, both in him and his partner.

If we refer to the organic erectile dysfunction, then the presence of the cyst can be considered as a physical element which directly contributed to the occurrence of erectile dysfunction, but the mechanism of appearance in the case de- 
scribed by us, is an exclusively non-organic one. If the cyst caused a chronic pain which would influence the ability to pay attention to sexual stimuli with decreased sexual arousal, then we could have talked about a direct influence of the cyst on the erectile function.

Thus, the possibility of establishing the type of erectile dysfunction within penile cystic formations requires clear elucidation of its effect on the sexual function at all levels.

The treatment tactic aimed at removing the trigger factor: the cyst excision. However, if necessary, the patient would also be prescribed drug therapy to remove the anxious factor. After surgery recovery and appropriate scarring, the patient reported a complete recovery of his erectile function, with significant improvement in self-confidence, also due to the gained esthetic aspect due to the cyst resection and so that the administration of the auxiliary therapy was not required. We consider the discussion with the patient extremely important to explain all the mechanisms which led to its erectile dysfunction, in particular the conviction that there is no organic factor.

This case is unique due to the fact that, besides the unspecific presentation of a hydrocistome (i.e. in a less common region: on the penis), the case is of interest also from the point of view of sexual problems, by explaining in detail all the mechanisms leading to the association of the sexual dysfunction.

\section{Conclusions}

Cystic formations located in the penis region also need to be considered as triggering factors for erectile dysfunction. In the absence of local pain sensations and disturbing cosmetic defect, other psychogenic mechanisms, cognitive and cultural, need to be excluded.

In conclusion, we can talk about the impact of a physical factor on erectile function through predisposition, triggering and maintenance mechanisms exclusively non-organic.

\section{Acknowledgements}

As we decided to bring the attention to the international medical community on the erectile dysfunction induced by psychogenic mechanisms due to anatomical penile disorders, we have been helped and supported by a long list of friends and colleagues. We may not be able to acknowledge you individually here, but please know your conversation, email, or encouragement has been invaluable.

\section{References}

[1] Warrier, S., Mohammed, K. and Safia, B. (2003) Multiple Apocrine Hydrocystoma- An Uncommon Presentation. Indian Journal of Dermatology, Venereology and Leprology, 69, 64-65. http://www.ijdvl.com/text.asp?2003/69/7/64/5862

[2] Jain, A., Majumdar, B., Sen, S., Samanta, A., Sen, D. and Tiwari, P. (2014) An Enlarging Cyst of the Penis: Unusual Presentation of a Cystic Disorder. Journal of Pakistan Association of Dermatologists, 24, 365-367.

[3] Liu, Y.S., Wang, J.S. and Li, T.S. (2010) A 25-Year-Old Man with a Dome-Shaped 
Translucent Nodule on the Glans Penis. Dermatologica Sinica, 28, 177-178. https://doi.org/10.1016/S1027-8117(10)60039-0

[4] Samplaski, M.K., Somani, N. and Palmer, J.S. (2009) Apocrine Hydrocystoma on Glans Penis of a Child. Urology, 73, 800-801.

https://doi.org/10.1016/j.urology.2008.03.008

[5] Rosen, R.C. (2001) Psychogenic Erectile Dysfunction. Urologic Clinics, 28, 269-278. https://doi.org/10.1016/s0094-0143(05)70137-3

[6] Jong, D.C. (2009) The Role of Attention on Sexual Arousal: Implication for Treatment of Sexual Dysfunction. Journal of Sex Research, 46, 237-248.

https://doi.org/10.1080/00224490902747230

[7] Abrahamson, D.J., Barlow, D., Beck, J.G., Sakheim, D.K. and Kelly, J.P. (1985) The Effect of Attentional Focus and Partner Responsiveness on Sexual Responding: Replication and Extension. Archives of Sexual Behavior, 14, 361-371. https://doi.org/10.1007/BF01550851

[8] Van Lankveld, J.J. and Van den Hout, M.A. (2004) Increasing Neutral Distraction Inhibits Genital But Not Subjective Sexual Arousal of Sexually Functional and Dysfunctional Men. Archives of Sexual Behavior, 33, 549-558. https://doi.org/10.1023/B:ASEB.0000044739.29113.73

[9] Nobre, P. and Gouveia, J.P. (2000) Erectile Dysfunction: An Empirical Approach on Beck's Cognitive Theory. Sexual and Relationship Therapy, 15, 351-366. https://doi.org/10.1080/713697434

[10] Brien, S.E., Smallegange, C., Gofton, W.T., Heaton, J.P.W. and Adams, M.A. (2002) Development of Rat Model of Sexual Performance Anxiety: Effect of Behavioral and Pharmacological Hyperadrenergic Stimulation on APO-Induced Erection. International Journal of Impotence Research, 14, 107-115. https://doi.org/10.1038/sj.ijir.3900836

[11] Maggi, M., Filippi, S., Ledda, F., Magini, A. and Forti, G. (2000) Erectile Dysfunction: From Biochemical Pharmacology to Advances in Medical Therapy. European Journal of Endocrinology, 143, 142-154. https://doi.org/10.1530/eje.0.1430143

[12] Rowland, D.L., Lechner, K.H. and Burnett, A.L. (2012) Factors Contributing to Psychoaffective Differences among Men with Sexual Dysfunction in Response to a Partnered Sexual Experience. Journal of Sex and Marital Therapy, 38, 115-127. https://doi.org/10.1080/0092623X.2011.569640

[13] Hale, V.E. and Strassberg, D.S. (1990) The Role of Anxiety on Sexual Arousal. Archives of Sexual Behavior, 19, 569-581. https://doi.org/10.1007/BF01542466 
Submit or recommend next manuscript to SCIRP and we will provide best service for you:

Accepting pre-submission inquiries through Email, Facebook, LinkedIn, Twitter, etc. A wide selection of journals (inclusive of 9 subjects, more than 200 journals)

Providing 24-hour high-quality service

User-friendly online submission system

Fair and swift peer-review system

Efficient typesetting and proofreading procedure

Display of the result of downloads and visits, as well as the number of cited articles Maximum dissemination of your research work

Submit your manuscript at: http://papersubmission.scirp.org/

Or contact asm@scirp.org 